\title{
FATORES QUE INFLUENCIAM NA ESTRUTURA DE CAPITAL DAS EMPRESAS LISTADAS NA BOVESPA
}

\author{
IDENTIFICATION OF INTERNATIONAL CLUSTERS \\ BASED ON THE HOFSTEDE'S CULTURAL DIMENSIONS
}

Recebido $17 / 08 / 2012$

Aceito $18 / 08 / 2012$

Pâmela Amado Tristão ${ }^{1}$ Vanessa Rabelo Dutra ${ }^{2}$

\section{RESUMO}

O objetivo deste trabalho é estudar a influência das variáveis independentes, porte, rentabilidade, crescimento e tangibilidade na estrutura de capital das empresas listadas na Bovespa (Bolsa de Valores de São Paulo) no ano de 2010. Para tanto, foi realizado um estudo descritivo e quantitativo. Para o alcance dos objetivos propostos, foram realizadas regressões múltiplas com as variáveis independentes e com a variável dependente grau de endividamento, a partir dos dados coletados, através das demonstrações financeiras das empresas. Concluiu-se que conjuntamente as variáveis independentes apresentam influência significante no grau de endividamento. Porém, quando analisadas separadamente, a única variável que apresentou influência no grau de endividamento foi a tangibilidade. As demais variáveis, porte, rentabilidade e crescimento, não apresentaram relevância nos modelos testados. Os resultados encontrados nesta pesquisa corroboram os estudos apresentados por Lemes Jr. e Da Costa Jr. (2006). Sugere-se que sejam realizados estudos futuros, analisando diferentes variáveis na estrutura de capital.

Palavras-chave: Estrutura de capital; Porte; Crescimento; Rentabilidade e Tangibilidade

${ }^{1}$ Administradora. Graduada pela Universidade Federal do Pampa- UNIPAMPA - Campus Sant'Ana do Livramento. E-mail: pamelamado@hotmail.com

${ }^{2}$ Docente do Curso de administração da Universidade Federal do Pampa. E-mail: vanessadutra@unipampa.edu.br 


\section{ABSTRACT}

The aim of this work is to study the influence of variables size, profitability, growth and tangibility in the capital structure of firms which belong to the São Paulo Stock Exchange (BOVESPA) in 2010. Concerning this, it was developed a descriptive and quantitative study. It was made a multiple regression using the size, profitability, growth and tangibility as independent variables and the level of indebtedness as dependent variable, based on the data from the firms' financial demonstrative. It has been concluded that the independent variables show a significant influence in the level of indebtedness when analyzed together. Though, when analyzed separately the only one which has shown a considerable influence is the tangibility. The other variables size, profitability and growth did not show any sign of influence in the regression models. The results obtained corroborate for future studies analyzing different variables in the capital structure.

Keywords: capital structure, size, profitability, growth and tangibility.

\section{INTRODUÇÃO}

Na área de finanças, um dos temas mais relevantes é a tomada de decisão, o qual gera uma grande polêmica no que diz respeito à forma com que as empresas escolhem a adoção ou não de um projeto. Um dos fatores que auxiliam na tomada dessa decisão é o custo do capital. Segundo Costa Jr. e Lemes Jr. (2006), o custo de capital determina a taxa mínima de retorno do projeto, avaliando sua viabilidade ou inviabilidade.

A importância do estudo da Teoria da Estrutura de Capital é relevante em dois aspectos, pois além de buscar a relação entre uma estrutura de capital ótima e seus custos reduzidos, também busca identificar quais fatores são preponderantes no momento de determinar as formas de financiamento para os projetos utilizados.

Para Durand $(1952,1959)$, pioneiro no estudo, existe uma estrutura ótima, a qual o próprio autor defendia. Em contrapartida, Modigliani e Miller, nos estudos realizados em 1958 e 1963, a partir de observação de certas premissas, advogavam irrelevante a forma com que as empresas se financiam. Apesar do aprofundamento teórico dos estudos publicados acerca da estrutura de capital, nenhum deles conseguiu com exatidão, encontrar sua existência ótima, a qual pudesse ser perseguida pelas empresas. (PEROBELLI e FAMA, 2003; COSTA JR. e LEMMES JR. 2006).

Autores como Perobelli e Famá (2003) afirmam que uma das variáveis que influenciam a estrutura de caixa é o porte da empresa. Isso envolve a rentabilidade, comumente relacionada ao endividamento; o crescimento que avalia as oportunidades de crescimento e investimento apresentadas às empresas; e, por fim, a tangibilidade, que é um fator de relevância, pois grande maioria das empresas que possuem ativos intangíveis ou oportunidade de crescimento tende a contrair menos dívida. Estes autores afirmam ser de fundamental importância a influência dessas variáveis. Logo, o objetivo deste trabalho é estudar a influência das variáveis porte, crescimento, rentabilidade e tangibilidade na estrutura de capital das empresas listadas na Bovespa, no ano de 2010.

\section{ESTRUTURA DE CAPITAL}

Ao optar por um determinado investimento, Perobelli e Famá (2003) afirmam que é fundamental que os custos de financiamento sejam apurados, sendo estes tão relevantes, que muitas teorias surgiram a fim de combinar de forma ótima o capital próprio e o endividamento, com o propósito de maximizar os lucros da empresa.

Dessa forma, a estrutura de capital é a disposição escolhida dos recursos a serem utilizados do financiamento da empresa, compostas as fontes de seu financiamento (GROPPELLI 
e NIKBAKHT, 1999), ou seja, a estrutura de capital de uma empresa é composta basicamente pelo mix de débito e equidade, desde que considerados apropriados para realçar suas operações. A seguir, serão apresentadas as mais relevantes teorias sobre a estrutura de capital, desde o artigo publicado por Modigliani e Miller (1958) até as teorias mais recentes.

\subsection{Estrutura de Capital: evolução histórica}

Partindo de um viés clássico, Durand (1952) questionava sobre a decisão racional do gestor, de forma a combinar o capital próprio e o de terceiros. De acordo com os estudos realizados por Forte (2010), Durand estudava a forma que o gestor aplicava até conseguir o seu custo médio ponderado de capital. Sua síntese teórica é conhecida como Teoria Convencional ou Tradicional, pois, segundo ele, quanto menos a empresa investir com o seu capital próprio, maior será sua maximização. Isso porque o capital de terceiros, se utilizado de forma correta, incorre juros mais baixos que o de patrimônio líquido se utilizado um nível considerado ótimo. Caso a utilização do capital de terceiros exceda esse nível, ocorre um aumento nos fatores de risco dentro da empresa, bem como nas possibilidades de se atingir uma estrutura de capital de forma negativa.

Em sequência, os estudos de Modigliani e Miller (1963) contribuíram de forma significativa para os estudos a respeito da estrutura de capital e sua respectiva composição. As duas pesquisas foram realizadas dentro de um paradigma neoclássico, ambas buscavam a otimização da utilidade sob a ótica da empresa.

A primeira delas, que trabalha com a Irrelevância da estrutura de capital, foi realizada em 1958 e afirma que o mercado de uma empresa não tem ligação com o seu capital, ou seja, segundo os pesquisadores, uma série de condições restritas, como impostos para pessoa física, custos de corretagens, e condições para empréstimos, não exercem nenhuma influência na estrutura de capital das empresas.

Com base nesse estudo, Modigliani e Miller (1958) afirmavam que o custo da dívida é mais baixo que o custo de capital próprio, porém ambos aumentam com o crescimento de endividamento. Sobre essa acepção, Fama e Grava (2000) afirmam que, quando a dívida alavanca a totalidade dos fundos, esta se iguala ao capital acionário.

Em seu segundo estudo, Modigliani e Miller (1963) publicaram a teoria conhecida como Teoria da Compensação, contribuindo através da flexibilização de premissas. Nesse estudo, ao contrário da primeira teoria criada por eles, reconheceram haver um ganho devido à utilização da alavancagem financeira, por serem os juros descontados dos lucros na forma de despesa. Os autores também sugeriram que a estrutura de capital pode sofrer influência dos benefícios fiscais resultantes do endividamento.

Segundo Suhaila, Kila e Mahmood (2008), essa proteção aos juros permite às empresas pagarem juros inferiores do que seriam pagos se utilizada a equidade financeira. A teoria da Compensação justifica uma participação moderada de endividamento na estrutura de capital. Essa afirmação é confirmada por Myers (1984), que ressalta que a empresa irá se financiar através de endividamento, até o ponto no qual o valor marginal das proteções fiscais, advindas do endividamento, não for superior ao do valor presente dos possíveis custos financeiros.

Posterior aos estudos de M\&M (1963), Jensen e Meckling (1976) realizaram seus estudos dentro de um paradigma neoclássico, através da inclusão de variáveis comportamentais dos agentes tomadores de decisão. Na Teoria dos Custos de Gestão, são agrupados o custo de agência da empresa, o comportamento gerencial, e a estrutura de propriedade da firma. Ainda de 
acordo com os achados de Jensen e Meckling, os gestores corporativos irão agir em busca de seus próprios interesses e buscarão salários maiores que os do mercado, regalias, e estabilidade no trabalho, o que conduz ao entendimento que tais gestores darão preferência aos investimentos que melhor se adaptarem ao seu propósito.

Segundo Karadeniz, Kandir, Balcilar e Onal (2009), a união dos estudos de Modigliani e Miller (1963), Jensen e Meckling (1976) deram origem à Teoria do Trade-off, a qual buscava a otimização dos resultados através da utilização de dívidas, incluindo a Teoria de Agência. A otimização, segundo Forte (2010), está baseada na busca da otimização de resultados, que se torna possível através da minimização dos custos, considerando-se os custos de falência e riscos da dívida. O mesmo autor afirma que a empresa busca primeiramente a fonte mais barata em sua máxima proporção, aumentando as outras até fazer com que o custo marginal de captação de fundos ultrapasse o ganho marginal gerado. Para isso, Myers (1984) afirma que seria necessário que a empresa encontrasse o resultante entre o custo e o benefício da dívida. Nesse mesmo paradigma, Mash (1982) concluiu que as empresas se comportam de acordo com essa teoria, através das estruturas escolhidas e dos fatores como tamanho e risco de falência. Ainda sobre os estudos acerca da estrutura de capital, foi estudada a Teoria da Hierarquia das Escolhas (Pecking Order Theory), a qual parte da discussão referente às informações assimétricas, em que os gestores têm mais conhecimento dos riscos, das perspectivas e dos valores da empresa em relação aos investidores externos. Myers (1984) confirma esse conceito, afirmando que, quando há algum anúncio por parte dos gestores, há alterações no valor das empresas. Nessa teoria, Myers afirma que não há uma estrutura-alvo bem definida a ser seguida, pois existem, segundo o autor, duas fontes de capitais próprios - interna e externa -, uma na parte superior da hierarquia e outra na de baixo. $\mathrm{O}$ autor afirma, também, que as empresas financiam seus investimentos preferencialmente com fundos gerados internamente; depois por meio de lucros retidos; seguidos do financiamento; e, por último, pela emissão de novas ações.

\subsection{Variáveis relevantes para o estudo da Estrutura de Capital}

De acordo com estudos realizados por Ortiz, Pilan e Carvalho (2008), existem componentes que podem ser considerados como determinantes para a estrutura de capital das empresas, como, por exemplo, o tamanho, a rentabilidade e a tangibilidade de ativos; as oportunidades de crescimento; e os riscos sofridos pela empresa. Dessa forma, este estudo se baseia nos estudos de Lemmes Jr. e Da Costa Jr. (2006) e busca identificar a relação do porte, da rentabilidade, do crescimento e a tangibilidade com a estrutura utilizada pelas empresas estudadas.

\subsubsection{Porte}

Alguns autores, como Scott e Martin (1975), Ferri e Jones (1979) e Rajan e Zingales (1995), afirmam que a relação entre tamanho da empresa e grau de endividamento é positiva. Essa ideia parte do pressuposto que quanto maior a empresa, menor o seu risco de falência. O que, segundo Perobelli e Famá (2003), justifica-se pela maior acessibilidade dos recursos financeiros e maior diversificação dos seus negócios.

Corroborando esses estudos, Machado e Temoche Machado (2004) afirmam que na medida em que grandes empresas são mais diversificadas, estas obtêm mais facilidades no acesso ao mercado de capitais e, consequentemente, resultam em menor probabilidade de dificuldades financeiras e em menores custos de endividamento. 


\subsubsection{Rentabilidade}

"A rentabilidade indica quanto renderam os investimentos, e, portanto, qual o grau de êxito econômico da empresa" (MATARAZZO, 2003, p.175). Para Ross, Westerfield e Jaffe (2002), a rentabilidade é o quociente entre o valor presente dos fluxos de caixa futuros e os valores posteriores ao investimento inicial.

As empresas normalmente financiam seus investimentos via lucros retidos, endividamento, ou emissão de ações. Para Myers (1984), quanto maior rentabilidade da empresa, menor será seu endividamento, pois as empresas mais rentáveis adquirem maior capacidade de se financiarem através de suas atividades. Essa teoria é chamada de Pecking Order Theory.

\subsubsection{Crescimento}

As empresas que se encontram em fase de crescimento tendem a ter um baixo grau de endividamento, devido às altas oportunidades de investimento. Porém, empresas com baixo crescimento e poucas oportunidades de investimento apresentam índice de endividamento superior. Empresas com alto crescimento apresentam maior grau de certeza quanto à viabilidade de seus ganhos futuros. Essa idéia é confirmada por Brigham e Houston (1999), os quais afirmam que o fator incerteza reduz sua disposição de utilizar capital de terceiros.

A variável crescimento é encontrada em duas teorias: a teoria dos custos de falência e a teoria da hierarquia das escolhas. As empresas com alto potencial de crescimento, que não possuem recursos próprios suficientes para se financiarem, optariam por uma alavancagem financeira maior (MACHADO, TEMOCHE e MACHADO, 2004).

Para Black e Scholes (1973), o controle das ações de uma empresa alavancada poderia ser visto como opção de compra direta dos acionistas. Com isso, estes teriam incentivos ao optar por projetos que oferecessem grande taxa de retorno, mesmo que com amplo grau de incerteza quanto a sua probabilidade de sucesso. De acordo com Toy et al.; (1974); Kayo e Famá (1997), essa tendência é ainda maior em empresas em crescimento, por possuírem maior flexibilidade em suas escolhas de investimento. De forma que, quanto mais alto o custo do investimento, menos estimuladas as empresas seriam ao optar pela dívida.

\subsubsection{Tangibilidade}

Os ativos tangíveis são mais facilmente avaliados pelo mercado e mais propensos a relações de troca, (PEROBELLI e FAMÁ 2003). O nível de endividamento é maior entre as empresas que os oferecem como garantia, havendo, dessa forma, uma relação positiva entre o volume dos ativos tangíveis detidos pela empresa e o seu nível de endividamento. De forma contraditória, Lumby (1991); Thies e Klock (1992); Rajan e Zingales (1995) afirmam que com maior volume de ativos tangíveis as empresas poderiam endividar-se mais.

Baseadas nos estudos de Myers (1984), existem evidências indiretas indicando que o nível de empréstimo é determinado pelo valor e risco dos ativos da empresa e também pelo tipo de ativos que a mesma possui. Segundo o referido autor, as empresas que têm oportunidade de crescimento ou ativos intangíveis tendem a contrair menos dívidas do que empresas que têm ativos tangíveis.

De acordo com Brigham e Houston (1999, p.481), ativos de propósitos gerais são boas garantias por serem utilizados em muitos negócios, ao contrário de ativos com propósitos específicos. 


\section{MÉTODO DE PESQUISA}

Este estudo propõe uma análise da influência das variáveis de porte, rentabilidade, crescimento e tangibilidade na estrutura de capital das empresas listadas na Bovespa. Assim, o estudo utiliza o método quantitativo que, para Malhotra (2006, pg.154), procura identificar os dados e aplicá-los a alguma forma de análise estatística.

Para a coleta de dados, foram utilizados dados secundários, retirados da base de Economática ${ }^{\circledR}$ das empresas do ramo industrial a serem estudadas. Para o atingimento dos objetivos propostos, são analisadas as variáveis apresentadas no Quadro 1. Como técnica de análise, são aplicadas regressões lineares múltiplas.

\begin{tabular}{|c|c|c|c|c|}
\hline Variável & Tipo & Sigla & Fórmula & Descrição \\
\hline $\begin{array}{c}\text { Grau de Endividamen- } \\
\text { to }\end{array}$ & Dependente & GE & $\mathrm{GE}=\mathrm{CT} / \mathrm{PL}$ & $\begin{array}{l}\mathrm{CT}=\text { Exigível em Longo Pra- } \\
\text { zo PL= Patrimônio Líquido }\end{array}$ \\
\hline $\begin{array}{l}\text { Patrimônio Líquido (re- } \\
\text { presentativa de porte) }\end{array}$ & Independente & $\mathrm{PL}$ & PL & $\begin{array}{l}\text { Valor contábil de uma em- } \\
\text { presa, qual é a soma de } \\
\text { seu Patrimônio Líquido }\end{array}$ \\
\hline $\begin{array}{l}\text { Valor da Empresa de } \\
\text { Mercado (representa- } \\
\text { tiva de porte) }\end{array}$ & Independente & VM & VM & $\begin{array}{l}\text { Valor de mercado do total } \\
\text { de suas ações }\end{array}$ \\
\hline $\begin{array}{l}\text { Ativo Total (represen- } \\
\text { tativa de porte) }\end{array}$ & Independente & A. Total & AT & $\begin{array}{l}\text { Conjunto de bens e direitos } \\
\text { da empresa }\end{array}$ \\
\hline $\begin{array}{l}\text { Retorno sobre o Ativo } \\
\text { Total (representativa } \\
\text { de rentabilidade) }\end{array}$ & Independente & Roa & Roa $=\mathrm{LL} / \mathrm{AT}$ & $\begin{array}{l}\text { LL= Lucro Líquido } \\
\text { AT = Ativo Total }\end{array}$ \\
\hline $\begin{array}{l}\text { Retorno sobre o valor } \\
\text { da empresa (repre- } \\
\text { sentativa de rentabili- } \\
\text { dade) }\end{array}$ & Independente & Roa_vm & $\begin{array}{c}\text { Roa_vm }=\text { LL / } \\
\text { VM }\end{array}$ & $\begin{array}{c}\text { LL=Lucro Líquido } \\
\text { VM= Valor de Mercado de } \\
\text { uma Empresa }\end{array}$ \\
\hline $\begin{array}{l}\text { Retorno sobre o Patri- } \\
\text { mônio Líquido (repre- } \\
\text { sentativa de rentabili- } \\
\text { dade) }\end{array}$ & Independente & Roe & Roe $=\mathrm{LL} / \mathrm{PL}$ & $\begin{array}{c}\text { LL= Lucro líquido } \\
\text { PL= Patrimônio Líquido }\end{array}$ \\
\hline $\begin{array}{l}\text { Crescimento do Ativo } \\
\text { Total (representativa } \\
\text { de crescimento) }\end{array}$ & Independente & Cres_ativo & $\begin{array}{c}\text { Cres_ativo= } \\
{[\text { AT(ano } n) / A(} \\
\text { ano } n-1)]-1\end{array}$ & $\begin{array}{l}\text { AT } \mathrm{t}=\text { Ativo Total do Ano AT } \\
\mathrm{t}-1=\text { Ativo Total do Ano } \mathrm{t}-1\end{array}$ \\
\hline $\begin{array}{l}\text { Intangibilidade Implí- } \\
\text { cita (representativa da } \\
\text { tangibilidade) }\end{array}$ & Independente & Vm_PL & $\begin{array}{c}\text { VM_PL=VM/ } \\
\text { PL }\end{array}$ & $\begin{array}{c}\text { VM= Valor de Mercado da } \\
\text { Empresa } \mathrm{PL}=\text { Patrimônio } \\
\text { Líquido }\end{array}$ \\
\hline $\begin{array}{l}\text { Valor Colateral dos Ati- } \\
\text { vos (representativa da } \\
\text { tangibilidade) }\end{array}$ & Independente & Vca & $\begin{array}{c}\text { Vca }=(E+I B) \\
/ A T\end{array}$ & $\begin{array}{c}E=\text { estoque } \mathrm{IB}=\text { Imobilizado } \\
\text { Bruto } \mathrm{AT}=\text { Ativos Totais }\end{array}$ \\
\hline
\end{tabular}

Quadro 1: Variáveis Independentes de porte, rentabilidade, crescimento e tangibilidade; e variável dependente Grau de Endividamento. Fonte: Adaptado de Costa Jr. e Lemes Jr. (2006) 


\section{ANÂLISE DE RESULTADOS}

A população deste estudo é composta por 141 empresas do setor industrial. Essas empresas subdividem-se em 13 setores de atividades, sendo o setor têxtil o de maior representatividade em número de empresas, ocupando uma frequência de $16,3 \%$ no total das empresas estudadas, conforme ilustrado na Figura 1.

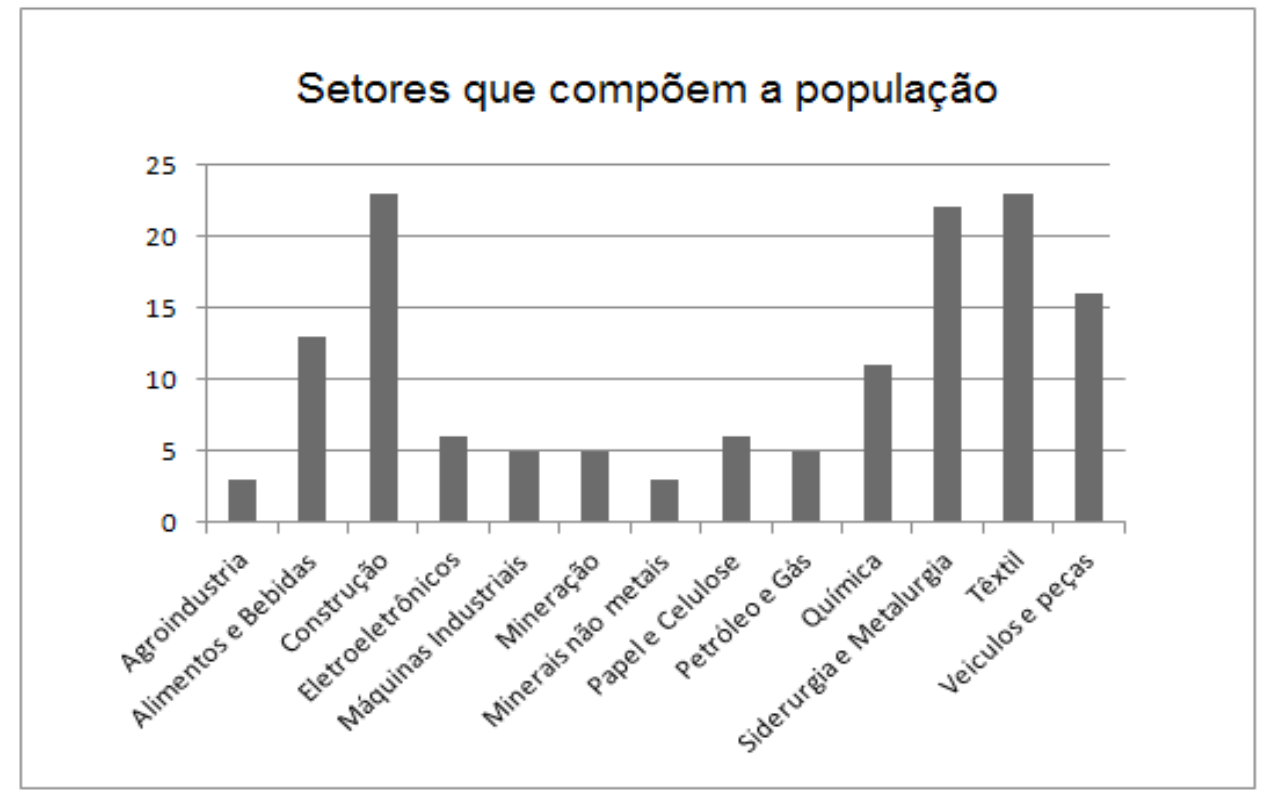

FIGURA 1 - Setores que compõem a população. Fonte: elaborada pela autora.

Os procedimentos estatísticos deste estudo contemplaram uma análise descritiva dos dados e da regressão linear múltipla. De acordo com Malhotra (2006; p. 497), a análise de regressão é um processo que analisa as relações associativas entre uma variável métrica dependente e uma ou mais variáveis independentes. Para o estudo, a equação de regressão é representada pela equação 1. Ge $=\alpha+\beta$ porte $+\beta$ rent $+\beta$ cresc $+\beta$ tang $+e$; na qual $y$ é a variável dependente, representada pelo do endividamento; $\beta$ é o coeficiente angular de regressão; $\beta$ porte é a variável que representa o porte; $\beta$ rent é a variável que representa a rentabilidade; $\beta c r e s c$ é a variável que representa o crescimento; $\beta$ tang é a variável que representa a tangibilidade; e é o coeficiente de perturbação que representa o erro.

Com o propósito de identificar a influência de porte, rentabilidade, crescimento e tangibilidade na variável dependente, ou seja, o grau de endividamento (GE), foi rodada uma regressão com 141 empresas, através do software Statistical Package for the Social Sciences (SPSS). É importante ressaltar que o número de empresas que compõem a população reduziu porque o teste excluiu automaticamente as variáveis missing wise.

Expressado pelo $r^{2}$, o coeficiente de Pearson representa a relação entre a variável explicada pelo modelo e a variação total, o que demonstra que as variáveis analisadas neste estudo exercem influência considerável na variável dependente GE, pois, como mostra a Tabela 1, a influência exercida pelas variáveis é significativa, uma vez que o valor de $r^{2}$ é de 0,75 , o que significa que $75 \%$ da variação no grau de endividamento é explicada pelo conjunto de variáveis compostas no modelo. Se observado o $\mathrm{R}$ ajustado, o conjunto dessas variáveis explicam $73 \%$ do comportamento do grau de endividamento. A deteç̧ão da autocorrelação foi testada através do teste Durbin Watson $(2,153)$, o que demonstra a independência dos resíduos. 
TABELA 1 Modelo sumarizado para as variáveis Porte, Rentabilidade, Crescimento e Tangibilidade

\begin{tabular}{c|c|c|c|c|c}
\hline Modelo & $\mathbf{R}$ & $\mathbf{R}^{\mathbf{2}}$ & $\mathbf{R}$ ajustado & Erro Padrão & Durbin-Watson \\
\hline 1 &, 866 & 0,75 & 0,733 & 168,65 & 2,153 \\
\hline
\end{tabular}

Fonte: Elaborada pela autora

Para testar a validade do modelo de regressão, procedeu-se o teste $F$, apresentado na Tabela 2, o qual permite testar a significância da regressão. $O$ valor para o teste $F$ foi de 43,738, mostrando que existe variação relativamente alta entre as variáveis estudadas.

TABELA 2 Análise de variância para as variáveis Porte, Rentabilidade, Crescimento e Tangibilidade

\begin{tabular}{c|c|c|c|c|c}
\hline $\begin{array}{c}\text { Fonte de } \\
\text { Variação }\end{array}$ & $\begin{array}{c}\text { Soma dos } \\
\text { Quadrados }\end{array}$ & $\begin{array}{c}\text { Graus de } \\
\text { Liberdade }\end{array}$ & $\begin{array}{c}\text { Quadrado } \\
\text { Médio }\end{array}$ & F & Significância \\
\hline Regressão & $1,120 \mathrm{E} 7$ & 9 & 1244074,81 & & \\
Resíduos & 3726166,390 & 131 & 28444,01 & 43,738 & $0,000^{*}$ \\
Total & $1,492 \mathrm{E} 7$ & 140 & & \\
\hline
\end{tabular}

Fonte: Elaborada pela autora

*Significante a $5 \%$

Após conhecer a influência conjunta das variáveis escolhidas, testou-se identificar a influência isolada de variáveis de cada grupo. Para isso, rodaram-se novas regressões para que se tornasse possível a análise dessas variáveis individualmente.

Ao analisar o Porte, identificaram-se, no referencial teórico, como medidas para esta variável, o patrimônio líquido; o valor de mercado; e o ativo total. Com o propósito de verificar essa possibilidade, testou-se primeiramente a influência exercida pela variável Porte, a qual é representada pela seguinte equação:

$G e=\alpha+\beta P L+\beta V M+\beta A T+e$ em que $G E$ é o grau de endividamento; $b$ é o coeficiente angular d regressão; $B P L$ é a variável representativa do Patrimônio Líquido; $B V M$ é o valor de mercado do total de suas ações; $B A T$ representa, através do Ativo Total, o conjunto de bens e direitos de uma empresa; $e$ é o coeficiente de perturbação que representa o erro.

TABELA 3 Modelo sumarizado de regressão para as variáveis de Porte

\begin{tabular}{c|c|c|c|c|c}
\hline Modelo & $\mathbf{R}$ & $\mathbf{R}^{\mathbf{2}}$ & $\mathbf{R}$ ajustado & Erro Padrão & Durbin-Watson \\
\hline $\mathbf{1}$ &, 035 & 0,001 & 0,019 & 319,68 & 1,970 \\
\hline
\end{tabular}

Fonte: elaborada pela autora

Observou-se que as variáveis de Porte não exercem influência no endividamento, pois o valor de $r^{2}$ obtido não se mostra significativo. Além disso, o teste $F$, com 0,59 , també grau de endividamento. Na Tabela 4, observa-se, através da analise de variância, que não há significância no modelo de regressão.

TABELA 4 Análise de variância para as variáveis de Porte

\begin{tabular}{c|c|c|c|c|c}
\hline $\begin{array}{c}\text { Fonte de } \\
\text { Variação }\end{array}$ & $\begin{array}{c}\text { Soma dos } \\
\text { Quadrados }\end{array}$ & $\begin{array}{c}\text { Graus de } \\
\text { Liberdade }\end{array}$ & $\begin{array}{c}\text { Quadrado } \\
\text { Médio }\end{array}$ & F & Significância \\
\hline Regressão & 18127,654 & 3 & 6042,551 & & \\
Resíduos & $1,513 \mathrm{E} 7$ & 148 & 102197,335 & 0,059 & $0,981^{*}$ \\
Total & $1,514 \mathrm{E} 7$ & 151 & * Significante a 5\%
\end{tabular}

$$
G e=\alpha+\beta R o a+\beta R o a_{-} v m+\beta R o e+e \text { Com o propósito de analisar uma }
$$

segunda variável independente (rentabilidade), foram excluídas todas as demais variáveis, 
restando apenas o retorno sobre o ativo, o retorno sobre valor da empresa e o retorno sobre o patrimônio líquido, que têm sua representação pela seguinte equação:

É possível observar, na Tabela 5, que a variável rentabilidade, assim como a variável porte, não exerce influência no grau de endividamento, como é mostrado pelo $r^{2}$ de aproximadamente $0,4 \%$. O teste $F$ assumiu valor 43,738 , significativo a $5 \%$, ou seja, o ajuste geral do modelo comprova ser adequado.

TABELA 5 Modelo Sumarizado de regressão para a variável Rentabilidade

\begin{tabular}{c|c|c|c|c|c}
\hline Modelo & $\mathbf{R}$ & $\mathbf{R}^{2}$ & $\mathbf{R}$ ajustado & Erro Padrão & Durbin-Watson \\
\hline $\mathbf{1}$ &, 210 & 0,044 & 0,023 & 322,69 & 1,968 \\
\hline
\end{tabular}

Fonte: Elaborada pela autora

O teste de significância deve apresentar valores menores do que 0,05, o que demonstraria a rejeição da hipótese nula do estudo. Logo, com significância 0,103, (Tabela 6), aceita-se a hipótese de que não há influência da Rentabilidade no grau de endividamento.

TABELA 6 Análise de variância das variáveis de Rentabilidade

\begin{tabular}{c|c|c|c|c|c}
\hline $\begin{array}{c}\text { Fonte de } \\
\text { Variação }\end{array}$ & $\begin{array}{c}\text { Soma dos } \\
\text { Quadrados }\end{array}$ & $\begin{array}{c}\text { Graus de } \\
\text { Liberdade }\end{array}$ & $\begin{array}{c}\text { Quadrado } \\
\text { Médio }\end{array}$ & F & Significância \\
\hline Regressão & 656385,818 & 3 & 218795,273 & 2,101 & $0,103^{a}$ \\
Resíduos & $1,427 \mathrm{E} 7$ & 137 & 104134,700 & \\
Total & $1,492 \mathrm{E} 7$ & 140 & & \\
\hline
\end{tabular}

Fonte: Elaborada pela autora * Significante a $5 \%$

Com o propósito de testar a influência da variável Crescimento na Estrutura de Capital das empresas estudadas, foi rodada uma nova regressão simples, representada por $G E=\alpha+b$ crescativo $+e$. Esta apresentou um $r^{2}$ insignificante, dado que a variável Crescimento selecionada responderia por apenas 0,1\% (Tabela 7) da influência no grau de endividamento dessas empresas.

TABELA 7 Modelo sumarizado para a variável Crescimento

\begin{tabular}{c|c|c|c|c|c}
\hline Modelo & $\mathbf{R}$ & $\mathbf{R}^{\mathbf{2}}$ & $\mathbf{R}$ ajustado & Erro Padrão & Durbin-Watson \\
\hline $\mathbf{1}$ &, 23 & 0,001 & 0,006 & 317,65 & 1,971 \\
\hline
\end{tabular}

Fonte: Elaborada pela autora

Além disso, a Tabela 8 mostra, no teste $F$, valor não significante, o que comprova a hipótese apresentada, da não existência da influência desta variável no Grau de Endividamento. Isso é reafirmado pelo valor da significância $(0,779)$.

TABELA 8 Análise de variância para a variável de Crescimento.

\begin{tabular}{c|c|c|c|c|c}
\hline $\begin{array}{c}\text { Fonte de } \\
\text { Variação }\end{array}$ & $\begin{array}{c}\text { Soma dos } \\
\text { Quadrados }\end{array}$ & $\begin{array}{c}\text { Graus de } \\
\text { Liberdade }\end{array}$ & $\begin{array}{c}\text { Quadrado } \\
\text { Médio }\end{array}$ & F & Significância \\
\hline Regressão & 7976,830 & 1 & 7976,830 & & \\
Resíduos & $1,514 \mathrm{E} 7$ & 150 & 1009002,376 & 0,79 & $0,779 *$ \\
Total & $1,514 \mathrm{E} 7$ & 151 & & \\
\hline
\end{tabular}

Fonte: Elaborada pela autora

*Significante a $5 \%$

Uma quarta e última regressão foi rodada a fim da constatar a influência da Tangibilidade

do GE. Para esta, foram incluídos a tangibilidade implícita e o valor colateral, os ativos, formando a equação: $G e=\alpha+\beta v m_{p l}+\beta v c a+e$ 
Ao contrário da hipótese que afirma não existir influência entre a Tangibilidade e o Grau de Endividamento, os dados da Tabela 9 mostram que existe influência de $71 \%$ da variável tangibilidade no grau de endividamento.

TABELA 9 Modelo sumarizado de regressão para as variáveis de Tangibilidade

\begin{tabular}{c|c|c|c|c|c}
\hline Modelo & $\mathbf{R}$ & $\mathbf{R}^{2}$ & $\mathbf{R}$ ajustado & Erro Padrão & Durbin-Watson \\
\hline $\mathbf{1}$ &, 845 & 0,713 & 0,710 & 170,68 & 2,107 \\
\hline
\end{tabular}

Fonte valor: Elaborada pela autora

O teste $F$ apresenta o valor de 185,39 , ou seja, o ajuste geral do modelo é adequado ao nível de significância de 5\%, conforme se pode observar na Tabela 10.

TABELA 10 Análise de variância para as variáveis de Tangibilidade

\begin{tabular}{c|c|c|c|c|c}
\hline $\begin{array}{c}\text { Fonte de } \\
\text { Variação }\end{array}$ & $\begin{array}{c}\text { Soma dos } \\
\text { Quadrados }\end{array}$ & $\begin{array}{c}\text { Graus de } \\
\text { Liberdade }\end{array}$ & $\begin{array}{c}\text { Quadrado } \\
\text { Médio }\end{array}$ & F & Significância \\
\hline Regressão & $1,080 \mathrm{E} 7$ & 2 & 5401232,362 & & \\
Resíduos & 4340868,548 & 149 & 29133,346 & 185,397 & $0,000^{*}$ \\
Total & $1,514 \mathrm{E} 7$ & 151 & & & \\
\hline
\end{tabular}

Fonte: Elaborada pela autora * Significante a $5 \%$

Ambos os dados mostrados nas tabelas 09 e 10 mostram que a Tangibilidade exerce grande influência na estrutura de capital das empresas, o que ratifica as citações de diversos autores que afirmam que o endividamento é maior nas empresas que possuem ativos tangíveis, pois os mesmos podem ser dados como garantia de pagamento para as suas obrigações.

\section{CONSIDERAÇÕES FINAIS}

Muitas foram as teorias publicadas acerca da Estrutura de Capital desde o estudo pioneiro de Durand em 1952, o qual avaliava a atitude do gestor, bem como suas escolhas; e os estudos de Modigliani e Miller logo após, em 1958, os quais apresentaram pesquisas referentes à existência de uma série de condições restritas, como impostos e custos, alegando que essas variáveis não exercem influência na forma com que a empresa constrói seu mix de financiamento.

Além das teorias de Durand e Modigliani e Miller, as demais também apresentam a escolha da estrutura de capital segundo premissas dentro da empresa, confirmando a não existência de uma estrutura de capital ótima. Isso conduz ao entendimento de que devem ser avaliadas diferentes variáveis dentro da empresa, de acordo com cada segmento de mercado. Neste estudo, utilizou-se um corte transversal no ano de 2010. Foram utilizados elementos referentes a 141 empresas do ramo industrial listadas na Bovespa, sendo rodadas regressões lineares múltiplas, as quais tornaram possível avaliar a influência das variáveis porte, rentabilidade, crescimento e tangibilidade.

Neste estudo, através de uma análise de regressão, encontrou-se um $\mathrm{R}$ ajustado 0,73 ,ou ainda, $73 \%$ das variáveis no modelo explicam a variável dependente, ou seja, as variáveis de porte, rentabilidade, crescimento e tangibilidade explicam em $73 \%$ o grau de endividamento das empresas analisadas. Tais achados são coerentes com a teoria descrita e demonstram que 0 comportamento do grau de endividamento existente é um elemento relevante na manutenção dos objetivos das empresas.

No tocante das análises conjuntas, esses achados corroboram os estudos de Lemmes Jr. e da 
Costa Jr. (2006), que encontraram dependência das variáveis se analisadas conjuntamente.

Entretanto, para tornar os resultados obtidos ainda mais exatos, foram rodadas novas regressões a fim de analisar cada variável individualmente. Diferente dos achados de Lemes Jr. e Da Costa Jr, que encontraram influência apenas do porte na estrutura de capital das empresas, neste estudo, a variável tagibilidade mostrou-se relevante em todos os modelos testados. Essa maior influência foi comprovada através da análise do valor de mercado da empresa, do patrimônio líquido, do estoque, do imobilizado bruto e dos ativos totais. As variáveis porte, crescimento e rentabilidade apresentaram valores que demonstram não haver nenhuma influência destas na estrutura de capital das empresas estudas.

Oresultado obtido através da análise da tangibilidade apresentou valores que comprovam sua influência através das representativas de intangibilidade implícita e valor colateral dos ativos, mostrando que esta é a variável que demonstra maior influência.

Neste estudo, limitou-se a análise de apenas um ano, pois se utilizou de um corte transversal, o que não possibilitou verificar a persistência desse comportamento ao longo dos anos. Para estudos futuros, sugere-se a análise dos dados longitudinais, os quais poderão apresentar se essa influência permanece ao longo do tempo. Além disso, as variáveis independentes avaliadas nesse estudo podem apresentar composições diferentes. A variável crescimento, que foi representada somente pelo crescimento do ativo total, poderá ser também analisada através do crescimento das receitas operacionais, o que pode influenciar os resultados a serem obtidos, provendo assim, um avanço da temática do grau de endividamento das empresas. 


\section{REFERÊNCIAS}

BRIGHAM, E. F.; HOUSTON, J. F. Fundamentos da Moderna Administração Financeira. Rio de Janeiro: Campus, 1999.p. 481

COSTA JR., Atair Ferreira; LEMES JR., Antônio Barbosa. Estrutura de Capital das Empresas Integrantes do İndice Ibx-Loo da Bolsa de Valores de São Paulo de 2000 a 2004. Salvador, 2006.

DURAND, D; Cost of debt and equity Funds for Business: trends and problems of measurement. New York: Conference in Research on Business Finance, 1952.

FAMÁ, R.; GRAVA, J.W. Liquidez e a teoria dos elementos causadores de insolvência. Caderno de Pesquisas em Administração, São Paulo: v.1, n12, 2000.

FORTE, Denis. Estrutura de Capital: Uma revisão de Trabalhos Empíricos e seus Resultados. Rio de Janeiro, 2010.

GROPPELLI, A.; NIKEBAKHT, E. Administração Financeira. 3a Ed. São Paulo: Saraiva, 1999.

JENSEN, M.C.; MECKLING, W. Theory of the firm: managerial behavior, agency costs, and capital structure. Journal of Financial Economics, 3(4), 305-360, 1976.

KARADENIZ, E.; KANDIR, S., Y.; BALCILAR, M., ONAL, Y., B.; Determinants of Capital Structure: evidence from Turkish lodging companies. International Journal of Contemporary Hospitality Management. Vol. 21, n. 5, 2009.

KAYO, E.K.; FAMÁ,R. Teoria de Agência e crescimento: evidências empíricas dos efeitos positivos e negativos do endividamento. Caderno de Pesquisa em Administração, São Paulo, v. 2, n. 5, 1997.

MACHADO, Márcio André Veras; TEMOCHE, Cézar Augusto Ruiz; MACHADO, Márcia Reis. Determinates da estrutua de caital das pequenas e médias empresas industriais da cidade de joão Pessoa/PB. In: Enanpad 2004.
Anais dos resumos dos trabalhos. Curitiba, Paraná, 2004. 17p.

MALHOTRA, N.K. Pesquisa d Marketing: Uma orientação Aplicada. 4 ed. Porto Alegre: Bookman, 2006.

MASH, P. The choice between equity and debt: an empirical study. The journal of Finance, Berkely, v.37, 1982.

MATARAZZO, Dante Carmine. Análise Financeira de Balanços. 6 ed. São Paulo: Atlas, 2003. p.175

MODIGLIANI, F.; MILLER, M. The cost of capital, corporation finance, and the theory of investment. American Economic Review, v. 48, n.3, p. 261-297, June 1958.

Corporate income taxes and the cost of capital: a correction, American Economic Review, v.53, n.3, p.433-443, June 1963.

MYERS, S. C. The Capital Structure Puzzle. Journal of Finance, Chicago: American Finance Association, 1984.

ORTIZ, Adriana Sousa; PILAN, Jovana; CARVALHO, Willian da Silva. Estrutura de Capital e Risco: Um estudo sobre a relação entre endividamento e risco para empresas de Capital Aberto. São Paulo, 2008.

PEROBELLI, Fernanda F. Cordeiro; FAMÁ, Rubens Fatores Determinantes da Estrutura de Capital para Empresas Latino-Americanas. RAC, v.7, n.1. Curitiba Jan/ Março de 2003.

RAJAN, R. G., ZilNGALES, L. What do we know about capital structure? Some evidence from international data. Journal of Finance, ed.50, 1995.

ROSS, Stephen A.; WESTERFIELD, Randolph W.; JAFFE, Jeffrey F. Administração Financeira Corporate Finance. São Paulo, Editora Atlas, 2002

SHUHAILA; KILA, Mat; MAHMOOD, Wan. Capital Structure and Firms Characteristics: Some Evidence from Malaysian Companies University of Tecnology MARA Terengganu, Wan Mansor, 2008. 